Filol. linguist. port., n. 14(1), p. 37-56, 2012.

\title{
A entoação das sentenças clivadas em português brasileiro e a interface sintaxe-fonologia ${ }^{1}$
}

\author{
Flaviane Romani Fernandes-Svartman ${ }^{2}$
}

\begin{abstract}
Resumo: Este trabalho, desenvolvido no quadro teórico da Fonologia Entoacional (cf. Pierrehumbert, 1980; Beckman and Pierrehumbert, 1986; Ladd 1996; Jun, 2005), visa ao estudo comparativo da estrutura entoacional das sentenças neutras e clivadas (sentenças clivadas, clivadas invertidas e clivadas invertidas reduzidas) do português brasileiro (doravante, PB). Conforme os resultados obtidos por Frota (1994), Vigário (1998) e Fernandes-Svartman (2007c), em estruturas sintáticas especiais do português europeu, o contorno entoacional sofre alterações locais e, algumas vezes, globais, se comparado ao contorno das sentenças neutras. Nossa hipótese é de que também em PB ocorram alterações no contorno entoacional de estruturas sintáticas especiais, como no caso das sentenças clivadas. Os resultados alcançados por este trabalho confirmam tal hipótese, na medida em que foram encontradas diferenças significativas entre o contorno entoacional das sentenças neutras e o contorno entoacional das sentenças clivadas do PB. Enquanto para as sentenças neutras foram encontrados acentos tonais associados a, praticamente, cada palavra prosódica da sentença e ausência de acentos frasais associados a fronteiras de frases fonológicas, para as sentenças clivadas, foram encontrados: (i) acento tonal associado obrigatoriamente à palavra prosódica cabeça da frase fonológica na qual o sujeito focalizado é mapeado; (ii) acento frasal associado opcionalmente à fronteira direita dessa mesma frase fonológica; e (iii) ausência de acentos tonais associados a palavras prosódicas intermediárias (entre a palavra prosódica cabeça da frase fonológica na qual o sujeito focalizado é mapeado e a palavra prosódica cabeça da última frase fonológica da frase entoacional). No caso das sentenças clivadas, a presença de acento frasal associado à fronteira direita da frase fonológica na
\end{abstract}

1 Uma versão preliminar deste trabalho, fruto do desenvolvimento da pesquisa de Doutorado "Ordem e preenchimento em português: sintaxe e prosódia" (Fernandes, 2007a), foi apresentada, sob a forma de comunicação, no GT "Abordagens acústicas em estudos segmentais e suprassegmentais" do VIII Encontro do CELSUL, realizado de 29 a 31 de outubro de 2008. No desenvolvimento do presente trabalho, agradeço ao apoio financeiro da Fundação de Amparo à Pesquisa do Estado de São Paulo (processos FAPESP 03/13938-5 e 2011/50044-9), ao parecerista anônimo da revista Filologia e Linguística Portuguesa pelos comentários feitos à versão prévia à publicação e à Profa. Dra. Márcia Santos Duarte de Oliveira (c.p.) pelas considerações muito enriquecedoras acerca das estruturas clivadas e relativas do PB - ver seção "Considerações finais" deste artigo.

2 Universidade de São Paulo - flavianesvartman@usp.br 
qual o sujeito focalizado é mapeado pode, por hipótese, estar relacionada à codificação de uma posição sintática especial ocupada por esse sujeito em tais estruturas: fora de IP, na posição de especificador de CP.

Palavras-chave: Entoação; Fonologia; Português brasileiro; Sentenças clivadas.

\section{INTRODUÇÃO}

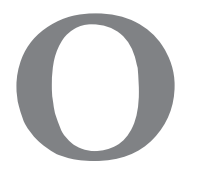

uso de sentenças clivadas é uma das maneiras de expressar focalização em PB - cf., entre outros, Kato e Raposo (1996); Modesto (2001); Fernandes (2007a). ${ }^{3}$ Nessa mesma variedade de português, encontramos diferentes tipos de estruturas clivadas, entre elas: sentenças clivadas, pseudo-clivadas, clivadas invertidas, clivadas invertidas reduzidas, conforme exemplificado, respectivamente em (1a), (1b), (1c) e (1d).

[Contexto: Estamos à espera das governadoras no gabinete. Percebo que você vê chegar alguém, então, pergunto a você:]

Quem chegou?

(1) a. Foram as governadoras que chegaram.

b. Quem chegou foram as governadoras.

c. As governadoras é que chegaram.

d. As governadoras que chegaram.

Trataremos aqui apenas das sentenças clivadas (1a), clivadas invertidas (1c) e clivadas invertidas reduzidas (1d) do PB em contexto de focalização informacional do sujeito.

3 Quanto aos diferentes tipos de focalização em PB, encontram-se a focalização informacional e a contrastiva. A focalização informacional apenas carrega uma informação nova no discurso ou sentença. Já a focalização contrastiva, além de carregar uma informação nova, também nega uma informação prévia. Essas duas formas de focalização em PB aparecem representadas, respectivamente, pelos exemplos em (Ia) e (Ib), nos quais o elemento focalizado aparece em negrito.

[O que o João pegou?]

(1) a. O João pegou a bola.

[O Pedro pegou a bola.]

b. (Não) $\mathbf{O}$ João pegou a bola. 
De acordo com os trabalhos de Frota (1994), Vigário (1998) e Fernandes-Svartman (2007c), em estruturas sintáticas especiais do português europeu (como sentenças com elementos deslocados, sentenças com advérbios em diferentes posições e com diferentes escopos e sentenças pseudo-clivadas), o contorno entoacional sofre alterações locais e, algumas vezes, globais. Com base nessa afirmação, nosso objetivo é verificar se, também em PB, a mesma afirmação pode ser feita. Ou seja, pretendemos buscar a confirmação ou não da hipótese de que, também em $\mathrm{PB}$, estruturas sintáticas especiais, como o caso das sentenças clivadas e clivadas invertidas (reduzidas ou não), podem ser codificadas prosodicamente através do contorno entoacional.

Para o alcance de nosso objetivo, analisaremos comparativamente a estrutura entoacional das sentenças neutras com a estrutura entoacional das sentenças clivadas (clivadas, clivadas invertidas e clivadas invertidas reduzidas) do PB. Essa análise comparativa consiste especificamente na descrição e análise comparativa do contorno entoacional das sentenças neutras e clivadas do PB, em termos de descrição e análise dos eventos tonais associados a tais contornos. $\mathrm{Na}$ realização dessa análise entoacional, valer-nos-emos do quadro teórico da Fonologia Entoacional (cf., entre outros, Pierrehumbert, 1980; Beckman and Pierrehumbert, 1986; Ladd 1996; Jun, 2005; e, especificamente para o PB, cf. Frota e Vigário, 2000; Tenani, 2002; Fernandes, 2007a, b).

O presente trabalho será apresentado nas próximas três seções. Na seção 2, intitulada "Corpus e metodologia", apresentaremos um detalhamento sobre o corpus utilizado neste trabalho e sobre a metodologia de obtenção e análise dos dados. Por sua vez, na seção 3, "Resultados e análise", apresentaremos os resultados provenientes da descrição e análise comparativa dos contornos entoacionais associados às sentenças neutras e clivadas do PB. Já na última seção, intitulada "Considerações finais", apresentaremos um resumo dos resultados encontrados e as conclusões a que chegamos acerca da hipótese que norteou o desenvolvimento deste trabalho.

\section{CORPUS E METODOLOGIA}

O corpus utilizado para análise neste trabalho é composto por 56 sentenças constituídas por verbos transitivos, inacusativos e inergativos. As palavras 
que compõem tais sentenças são, na grande maioria, formadas por consoantes sonorantes, consoantes vozeadas e por vogais (ex.: "meninas" [mi'ninas], "lago" ['lagu]). A escolha por tais segmentos na composição das palavras das sentenças teve como propósito minimizar perturbações microprosódicas no contorno entoacional que pudessem dificultar a análise entoacional, como no caso das perturbações microprosódicas causadas pelas consoantes obstruintes surdas. As sentenças utilizadas em nosso trabalho ainda variaram sistematicamente quanto ao número de sílabas e palavras prosódicas $(\omega)$ que compõem o sujeito e o predicado. O controle desse fator teve como intuito averiguarmos se o número de sílabas pretônicas e o número de palavras prosódicas que compõem os já referidos constituintes sintáticos podem afetar a atribuição de eventos tonais ao contorno entoacional das sentenças neutras e clivadas de PB.

A metodologia de obtenção dos dados consistiu na elaboração e aplicação de um questionário "semiaberto", contemplando contexto próprio para a obtenção de sentenças neutras e para a obtenção de sentenças com foco informacional no sujeito, como exemplificado, respectivamente, em (2) e (3). Durante a aplicação do questionário, a apresentação desses dois tipos de contextos foi intercalada com a apresentação de contextos distrativos aos falantes.

(2) Contexto para obtenção de sentenças neutras:

a. Contexto: Você sabe que as governadoras chegaram. Eu ouvi dizer que algo aconteceu, mas não sei exatamente o quê, então, pergunto a você:

$\mathrm{O}$ que aconteceu?

Ou:

b. Contexto: Leia a seguinte notícia:

"As governadoras chegaram."

(3) Contexto para a obtenção de sentenças com foco informacional no sujeito: Contexto: Estamos esperando as governadoras no gabinete. Eu percebo que você vê chegar alguém que eu ainda não vi, então, pergunto a você: Quem chegou?

O referido questionário foi aplicado duas vezes a três falantes nativas de $\mathrm{PB}$, procedentes da região de Campinas $(\mathrm{SP})$, pertencentes à mesma faixa etária (19 a 22 anos) e com o mesmo grau de escolaridade (estudantes universitárias). 
As sentenças produzidas pelas falantes foram gravadas a $16 \mathrm{kHz}$ com o uso de um gravador digital Panasonic, modelo US 360.

A metodologia de análise entoacional dos dados consistiu na transcrição dos eventos tonais associados ao contorno entoacional das sentenças, através do uso do programa computacional de análise de fala Praat (disponível em: <http://www.fon.hum.uva.nl/praat/ >) e com base no quadro teórico da Fonologia Entoacional (cf. Pierrehumbert, 1980; Beckman and Pierrehumbert, 1986; Pierrehumbert and Beckman, 1988; Ladd, 1996; Jun, 2005; e, especificamente para o PB, cf. Frota e Vigário, 2000; Tenani, 2002; Fernandes, $2007 \mathrm{a}, \mathrm{b})$.

\section{RESULTADOS E ANÁLISE}

\subsection{A entoação das sentenças neutras}

Ao todo foram produzidas 336 sentenças neutras: 56 sentenças X 3 falantes X 2 repetições. Dessas 336 sentenças, 335 foram utilizadas no desenvolvimento deste trabalho, dado que uma das sentenças foi produzida com foco no verbo por uma das falantes.

Como características entoacionais gerais desse tipo de sentença notam-se:

(i) Acentos tonais $\left(\mathrm{T}^{*}\right)^{4}$ associados opcionalmente a todas as palavras prosódicas $(\omega)$ do contorno entoacional - cf. também Fernandes (2007a, b); ${ }^{5}$

(ii) Acentos tonais associados obrigatoriamente a cada palavra prosódica cabeça de frase fonológica $(\phi)^{6}$ da frase entoacional entoacional $(\mathrm{I})^{7}-\mathrm{cf}$. também Frota e Vigário (2000); Tenani (2002); Fernandes (2007a, b);

4 Sobre acento tonal $\left(\mathrm{T}^{*}\right)$, acento frasal $(\mathrm{T})$ e tom de fronteira ( $\mathrm{T} \%$ ) no quadro da Fonologia Entoacional, cf. Pierrehumbert, 1980; Beckman e Pierrehumbert, 1986; Pierrehumbert e Beckman, 1988; Ladd, 1996; entre outros.

5 Sobre a formação e definição de palavra prosódica, cf. Nespor e Vogel, 1986; Selkirk, 1986, 1995, 2000; entre outros. Sobre palavra prosódica em português, cf. Schwindt, 2001; Vigário, 2003; Toneli, 2009; entre outros.

6 Sobre a formação e definição de frase fonológica, cf. Nespor e Vogel, 1986; Selkirk, 1986, 2000; entre outros. Sobre a frase fonológica em português, cf. Frota, 2000 e Tenani, 2002.

7 Sobre a formação e definição de frase entoacional, cf. Nespor e Vogel, 1986. Sobre a frase entoacional em português, cf. Frota, 2000 e Tenani, 2002. 
(iii) Ausência de acentos frasais ( $\mathrm{T}$ ) associados às fronteiras de frases fonológicas - cf. também Frota e Vigário (2000); Tenani (2002); Fernandes (2007a, b); e

(iv) Acento tonal $\mathrm{H}+\mathrm{L}^{*}$ associado à $\omega$ cabeça do último $\phi$ de $\mathrm{I}$ e tom de fronteira $\mathrm{L} \%$ associado opcionalmente à fronteira direita da frase entoacional - cf. também Cunha (2000); Frota e Vigário (2000); Tenani (2002); Fernandes (2007a, b); Serra (2009).

Quanto à característica (i), em 90\% de todas as palavras prosódicas que compõem as 335 sentenças neutras do nosso corpus foram encontrados acentos tonais associados a elas, independentemente de a palavra prosódica ser cabeça de frase fonológica ou não. No caso de palavras prosódicas nas quais não se encontrou acento tonal associado $(10 \%$ de todas as palavras prosódicas do corpus), tais palavras eram, em sua grande maioria, não cabeça de sintagma fonológico. Ainda cabe acrescentar que, para as palavras prosódicas compostas por mais de duas sílabas pretônicas, além dos acentos tonais encontrados associados às sílabas tônicas, foram encontrados tons adicionais $(\mathrm{H})$ associados à segunda ou à terceira sílaba pretônica da palavra. Encontramos $\mathrm{H}$ adicional em 24,1\% (20) das $83(100 \%)$ sentenças que continham palavras desse tipo no corpus. A característica (ii) foi encontrada para 328 (98\%) das 335 sentenças neutras e, em apenas 2,1\% (7) das mesmas 335 sentenças, não foi encontrada tal característica. Por sua vez, as características entoacionais apresentadas em (iii) e (iv) foram encontradas em 100\% das 335 sentenças neutras do corpus.

A representação em (4') da sentença neutra em (4), bem como a respectiva Figura 1, exemplificam as características entoacionais elencadas de (i) a (iv).

(4) As meninas belas lavaram as luvas.

(4') $\left[[(\right.$ as meNInas) $\omega$ (BElas) $) \phi[($ laVAram $) \omega] \phi[($ as LUvas $) \omega] \phi] I^{8}$

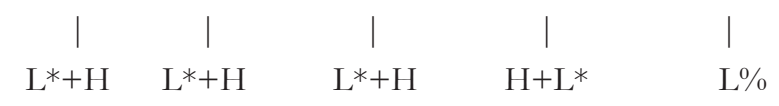

8 As sílabas em letras maiúsculas representam sílabas tônicas; as palavras prosódicas ( $\omega)$ são delimitadas por parênteses, as frases fonológicas $(\phi)$ por colchetes; e a frase entoacional (I) também é delimitada por colchetes. 


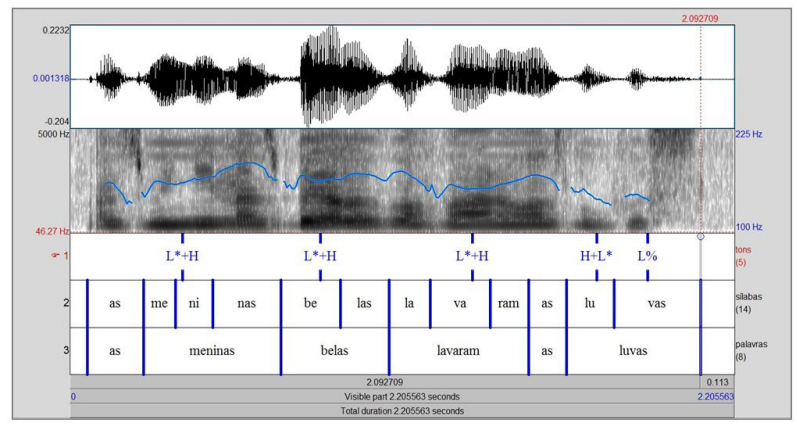

Figura 1. $\mathrm{F}_{0}$ da sentença "As meninas belas lavaram as luvas", produzida por uma falante de PB em contexto de obtenção de sentença neutra.

Através da observação da Figura 1, verificam-se:

(i) A associação de um acento tonal a cada palavra prosódica do contorno entoacional da sentença em (4), respectivamente: acento tonal $\mathrm{L}^{*}+\mathrm{H}$ associado à palavra prosódica (as meninas) $\omega$, acento tonal $\mathrm{L}^{*}+\mathrm{H}$ associado à palavra prosódica (belas) $\omega$, acento tonal $\mathrm{L}^{*}+\mathrm{H}$ associado à palavra prosódica (lavaram) $\omega$ e acento tonal $\mathrm{H}+\mathrm{L}^{*}$ associado à palavra prosódica (as luvas) $\omega$;

(ii) A associação de acentos tonais às palavras prosódicas cabeças de cada frase fonológica, respectivamente: acento tonal $\mathrm{L}^{*}+\mathrm{H}$ associado à palavra prosódica (belas) $\omega$, cabeça da frase fonológica [as meninas belas] $\phi$, acento tonal $\mathrm{L}^{*}+\mathrm{H}$ associado à palavra prosódica (lavaram) $\omega$, cabeça da frase fonológica [lavaram] $\phi$ e acento tonal $\mathrm{H}+\mathrm{L}^{*}$ associado à palavra prosódica (as luvas) $\omega$, cabeça da frase fonológica [as luvas] $\phi$

(iii) Ausência de acentos frasais associados às fronteiras das frases fonológicas que compõem a sentença em (4): [(as meninas) $\omega$ (belas) $\omega] \phi$, [(lavaram) $\omega]$ $\phi$ e $[$ (as luvas) $\omega] \phi$; e

(iv) Acento tonal $\mathrm{H}+\mathrm{L}^{*}$ associado à palavra prosódica (as luvas) $\omega$, cabeça da última frase fonológica da sentença e tom de fronteira $\mathrm{L} \%$ associado à fronteira direita da frase entoacional [as meninas belas lavaram as luvas]I.

\subsection{A entoação das sentenças Clivadas (Clivadas, clivadas invertidas e clivadas invertidas reduzidas)}

Em contexto de focalização informacional do sujeito, foram produzidas 168 estruturas clivadas pelas falantes de PB, sendo que, dessas 168, 74 foram produzidas como sentenças clivadas, 51, como clivadas invertidas e 43 
foram produzidas como sentenças clivadas invertidas reduzidas. As demais sentenças produzidas em contexto de focalização informacional do sujeito foram produzidas com outras estratégias de focalização pelas falantes: por exemplo, como sentenças na ordem linear sujeito-verbo(-objeto) ou sujeito-verbo(-advérbio) com o sujeito focalizado portando a proeminência principal da sentença.

As características entoacionais encontradas foram comuns a todos os tipos de estruturas clivadas (sentenças clivadas, clivadas invertidas e clivadas invertidas reduzidas) e consistem nas especificadas a seguir:"

(i) Acento tonal associado obrigatoriamente à palavra prosódica cabeça da frase fonológica na qual o sujeito focalizado é mapeado - cf. também Fernandes (2007a); Tenani e Fernandes-Svartman (2008);

(ii) Acento frasal associado opcionalmente à fronteira direita da frase fonológica na qual o sujeito focalizado é mapeado - cf. também Fernandes (2007a); Tenani e Fernandes-Svartman (2008);

(iii) Ausência de acentos tonais associados a palavras prosódicas intermediárias (entre a palavra prosódica cabeça da frase fonológica na qual o sujeito focalizado é mapeado e a palavra prosódica cabeça da última frase fonológica da frase entoacional) - cf. também Fernandes (2007a); Tenani e Fernandes-Svartman (2008); e

(iv) Acento tonal $\mathrm{H}+\mathrm{L}^{*}$ associado à palavra prosódica cabeça da última frase fonológica da frase entoacional (I), seguido de tom de fronteira $\mathrm{L} \%$ associado à fronteira direita desse mesmo constituinte prosódico ou apenas tom de fronteira $\mathrm{L} \%$ associado à fronteira direita da frase entoacional - cf. também Fernandes (2007a); Tenani e Fernandes-Svartman (2008).

As características (i), (iii) e (iv) foram encontradas para 100\% das 168 estruturas clivadas encontradas em nosso corpus. Quanto à característica (ii), em 78\% (131) das 168 estruturas clivadas, foram encontrados acentos frasais associados à fronteira direita da frase fonológica na qual o sujeito focalizado é mapeado e, no caso das 37 (22\%) sentenças clivadas restantes, não foram encontrados acentos frasais associados à fronteira direita da frase fonológica na qual o sujeito focalizado é mapeado, mas foram encontrados: (a) acento tonal

9 As mesmas características entoacionais encontradas para as estruturas clivadas do PB também foram encontradas por Fernandes (2007a, b) e Tenani e Fernandes-Svartman (2008) para as sentenças com foco prosódico (sentenças na ordem linear sujeito-verbo(-objeto) ou sujeito-verbo(-advérbio) com o sujeito focalizado portando a proeminência principal da sentença) dessa mesma variedade de português. 
associado obrigatoriamente à palavra prosódica cabeça da frase fonológica que contém o sujeito focalizado; e (b) acentos tonais associados opcionalmente a palavras prosódicas não cabeça desse mesmo tipo de frase fonológica. Isso posto, é possível afirmar que acento frasal associado à fronteira direita da frase fonológica na qual o sujeito focalizado é mapeado é uma característica entoacional preferencial (à ausência desse acento no mesmo contexto fonológico referido) para as estruturas clivadas do PB por nós analisadas.

As representações em (5'), (6’) e (7’) das respectivas sentença clivada em (5), sentença clivada invertida em (6) e sentença clivada invertida reduzida em (7), bem como as respectivas Figura 2, Figura 3 e Figura 4, ilustram as características entoacionais gerais encontradas para esses tipos de sentenças do nosso corpus.

(5) Foram as venezuelanas que lavaram as luvas.

(5’) $[[($ FOram $) \omega] \phi[($ as venezueLAnas $) \omega] \phi[$ (que laVAram) $\omega] \phi[($ as LUvas $) \omega] \phi] \mathrm{I}$

$$
\mathrm{L}^{*}+\mathrm{H} \quad \mathrm{L}^{-}
$$

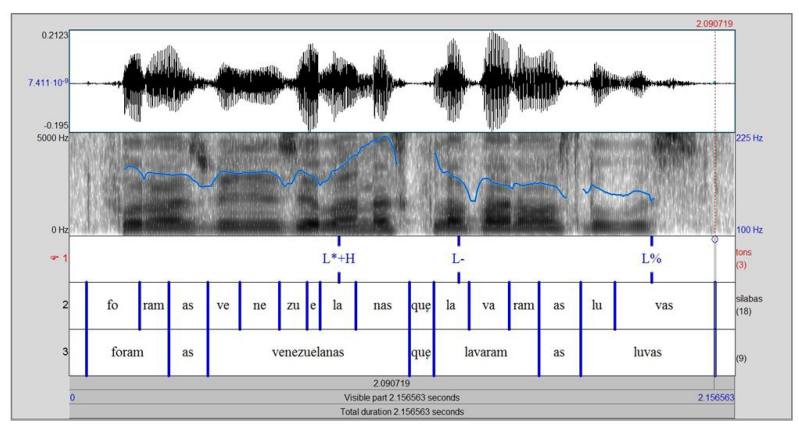

Figura 2. $\mathrm{F}_{0}$ da sentença "Foram as venezuelanas que lavaram as luvas", produzida por uma falante de PB em contexto de obtenção de foco informacional no sujeito.

(6) As velhas é que choraram.

(6’) $[[($ as VElhas) $\omega] \phi[(E ́) \omega] \phi[($ que choRAram) $\omega] \phi] I$

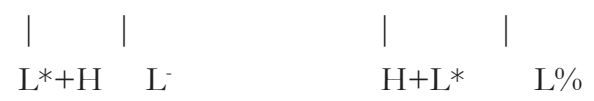




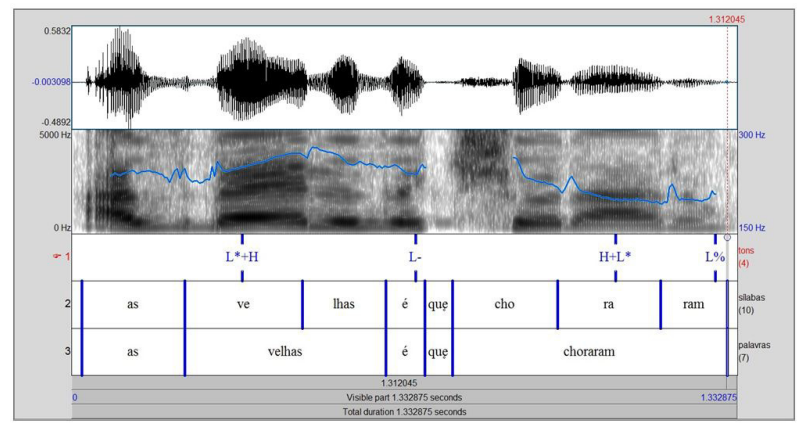

Figura 3. $F_{0}$ da sentença "As velhas é que choraram”, produzida por uma falante de PB em contexto de obtenção de foco informacional no sujeito.

(7) As alunas jovens que levaram as malas.

(7’) $[[($ as aLUnas $) \omega(J$ Ovens $) \omega] \phi[($ que leVAram $) \omega] \phi[($ as MAlas $) \omega] \phi] I$
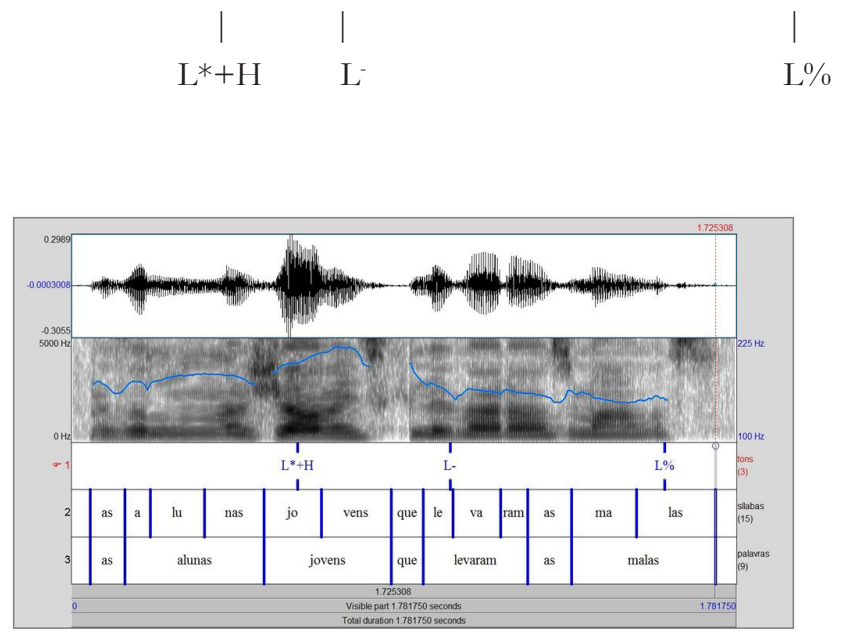

Figura 4. $\mathrm{F}_{0}$ da sentença "As alunas jovens que levaram as malas", produzida por uma falante de PB em contexto de obtenção de foco informacional no sujeito.

Através da observação da Figura 2, notam-se: (a) a associação do acento tonal $\mathrm{L}^{*}+\mathrm{H}$ à palavra prosódica cabeça (as venezuelanas) $\omega$ da frase fonológica [(as venezuelanas) $\omega] \phi$, na qual o sujeito focalizado é mapeado, e acento frasal L- associado à fronteira direita dessa mesma frase fonológica; (b) ausência de acentos tonais associados às palavras prosódicas que seguem o sujeito focalizado 
“as venezuelanas", respectivamente, (que lavaram) $\omega$ e (as luvas) $\omega$, e, inclusive, ausência de acento tonal associado à palavra prosódica que antecede tal sujeito, no caso, ausência de acento tonal associado à palavra prosódica (foram) $\omega$; e (c) presença de tom de fronteira L\% associado à fronteira direita da frase entoacional [foram as venezuelanas que lavaram as luvas]I.

Por sua vez, pela observação da Figura 3., verificam-se: (a) acento tonal $\mathrm{L}^{*}+\mathrm{H}$ associado à palavra prosódica cabeça (as velhas) $\omega$ da frase fonológica [(as velhas) $\omega] \phi$, na qual o sujeito focalizado é mapeado, e acento frasal L' associado à fronteira direita dessa mesma frase fonológica; (b) ausência de acentos tonais associados a palavras prosódicas intermediárias (entre a palavra prosódica cabeça da frase fonológica na qual o sujeito focalizado é mapeado e a palavra prosódica cabeça da última frase fonológica da frase entoacional), no caso, ausência de acento tonal associado à palavra prosódica (é) $\omega$; e (c) acento tonal $\mathrm{H}+\mathrm{L}^{*}$ associado à palavra prosódica cabeça (que choraram) $\omega$ da última frase fonológica da frase entoacional [as velhas é que choraram]I, seguido de tom de fronteira $\mathrm{L} \%$ associado à fronteira direita desse mesmo constituinte prosódico.

Finalmente, com base na observação da Figura 4, podemos notar: (a) acento tonal $\mathrm{L}^{*}+\mathrm{H}$ associado à palavra prosódica cabeça (jovens) $\omega$ da frase fonológica [(as alunas) $\omega$ (jovens) $\omega] \phi$, na qual o sujeito focalizado é mapeado, e acento frasal L associado à fronteira direta dessa mesma frase fonológica; (b) ausência de acentos tonais associados às palavras prosódicas que seguem o sujeito focalizado, respectivamente, (que levaram) $\omega$ e (as malas) $\omega$; e (c) tom de fronteira $\mathrm{L} \%$ associado à fronteira direita da frase entoacional [as alunas jovens que levaram as malas]I.

Ao compararmos os diferentes tipos de sentenças clivadas de PB abordados neste trabalho (sentenças clivadas, clivadas invertidas e clivadas invertidas reduzidas), quanto às características entoacionais por elas apresentadas, nota-se que essas estruturas clivadas apresentam o mesmo padrão entoacional, ou seja, encontramos as mesmas características entoacionais para todas elas, mas não encontramos características entoacionais que as diferenciem. O padrão entoacional comum encontrado para essas estruturas pode ser definido pela presença das seguintes características entoacioanais: (i) acento tonal associado obrigatoriamente apenas à w cabeça da frase fonológica na qual o sujeito é mapeado; (ii) acento frasal opcionalmente associado à fronteira direita desse mesmo constituinte prosódico; e (iii) ausência de acentos tonais associados a 
palavras prosódicas intermediárias (entre a palavra prosódica cabeça da frase fonológica na qual o sujeito focalizado é mapeado e a palavra prosódica cabeça da última frase fonológica da frase entoacional).

\subsection{Comparação entre a entoação das sentenças neutras e a entoação das estruturas clivadas do PB}

Da comparação entre a estrutura entoacional das sentenças neutras e a estrutura entoacional das estruturas clivadas do PB, verificam-se diferenças muito significativas entre elas. Enquanto no contorno entoacional das sentenças neutras encontramos acentos tonais $\left(\mathrm{T}^{*}\right)$ associados a, praticamente, cada palavra prosódica $(\omega)$ da frase entoacional $(\mathrm{I})$ e ausência de acentos frasais $\left(\mathrm{T}^{\prime}\right)$ associados às fronteiras de frases fonológicas $(\phi)$, no contorno das sentenças clivadas e clivadas invertidas (reduzidas ou não) do PB, encontramos acento tonal associado obrigatoriamente apenas à $\omega$ cabeça da frase fonológica na qual o sujeito é mapeado, acento frasal opcionalmente associado à fronteira direita desse mesmo constituinte prosódico e ausência de acentos tonais associados a palavras prosódicas intermediárias (entre a palavra prosódica cabeça da frase fonológica na qual o sujeito focalizado é mapeado e a palavra prosódica cabeça da última frase fonológica da frase entoacional).

Tais diferenças podem ser comprovadas de maneira quantitativa através da observação da Tabela 1.

\begin{tabular}{c|c|c|c|c}
\hline Tipo de sentença & $\mathbf{N}^{\text {o de sentenças }}$ & $\mathbf{N}^{\text {o de } \omega \mathbf{s}}$ & $\mathbf{N}^{\circ}$ de $\mathbf{T}^{*}$ & $\mathbf{N}^{\mathbf{0}}$ de $\mathbf{T}^{-}$ \\
\hline Neutra & 335 & 984 & 889 & 0 \\
\hline Clivada & 74 & 289 & 165 & 58 \\
\hline Clivada invertida & 51 & 198 & 88 & 33 \\
\hline $\begin{array}{c}\text { Clivada invertida } \\
\text { reduzida }\end{array}$ & 43 & 130 & 66 & 40 \\
\hline
\end{tabular}

Tabela 1 Número de palavras prosódicas versus número de eventos tonais

A Tabela 1. revela que, para as sentenças neutras, enquanto há uma quantidade alta de acentos tonais (889 T*s) atribuídos à totalidade das senten- 
ças, quantidade essa próxima à quantidade de palavras prosódicas (984 $\omega$ s) que compõem as mesmas, não há nenhum acento frasal ( 0 T') associado à fronteira de frases fonológicas dessas sentenças. Já no caso das estruturas clivadas, a quantidade de acentos tonais atribuídos às sentenças (respectivamente: 165 T*s para as sentenças clivadas, $88 \mathrm{~T}^{*}$ s para as clivadas invertidas e $66 \mathrm{~T}^{*} \mathrm{~s}$ para as sentenças clivadas invertidas reduzidas) é bem menor que o número de palavras prosódicas que as compõem (respectivamente: 289 فs compondo sentenças clivadas, 198 ws compondo sentenças clivadas invertidas e $130 \omega \mathrm{s}$ compondo clivadas invertidas reduzidas), além de haver também acentos frasais atribuídos ao contorno dessas mesmas estruturas (58 T's para as sentenças clivadas, 33 T`s para as sentenças clivadas invertidas e 40 T`s para as clivadas invertidas reduzidas).

Comparando a densidade tonal (proporção de acentos tonais em relação ao número de palavras prosódicas) nos diferente tipos de sentenças aqui analisados, constata-se que a densidade tonal é muito mais alta no caso das sentenças neutras do que no caso das estruturas clivadas, como pode ser atestado pela observação dos dados apresentados na Tabela 2.

\begin{tabular}{c|c}
\hline Tipo de sentença & Densidade tonal \\
\hline Neutra & $90 \%$ \\
\hline Clivada & $57 \%$ \\
\hline Clivada invertida & $44 \%$ \\
\hline Clivada invertida reduzida & $51 \%$ \\
\hline
\end{tabular}

Tabela 2. Densidade tonal: proporção de acentos tonais em relação ao número de palavras prosódicas nas sentenças

Enquanto nas sentenças neutras a densidade tonal é de 90\% (praticamente um acento tonal atribuído a cada palavra prosódica da sentença), nas estruturas clivadas essa densidade é bem menor: densidade tonal de $57 \%$ para as sentenças clivadas, densidade tonal de $44 \%$ para as sentenças clivadas invertidas e densidade tonal de 51\% para as sentenças clivadas invertidas reduzidas. No caso das estruturas clivadas, a baixa densidade tonal é explicada pelo fato de só ser obrigatória a atribuição de acento tonal à palavra prosódica cabeça da 
frase fonológica na qual é mapeado o sujeito focalizado e haver ausência de acentos tonais atribuídos a palavras prosódicas intermediárias (entre a palavra prosódica cabeça da frase fonológica na qual o sujeito focalizado é mapeado e a palavra prosódica cabeça da última frase fonológica da frase entoacional).

Ainda quanto à densidade tonal das sentenças neutras e das estruturas clivadas, cabe notar uma diferença interessante entre o PB e o português europeu (PE). Conforme os resultados obtidos por Fernandes-Svartman (2007c), há uma quantidade maior de acentos tonais associados ao contorno entoacional das sentenças pseudo-clivadas do PE, se comparada à quantidade de acentos tonais associados ao contorno das sentenças neutras da mesma variedade. Em PB, percebemos uma inversão desses resultados: há mais acentos tonais atribuídos ao contorno das sentenças neutras e menos acentos tonais atribuídos ao contorno das estruturas clivadas. Independentemente dessa inversão de resultados nas duas variedades de português, nota-se que ambas codificam prosodicamente de maneira diferente sentenças neutras e estruturas sintáticas especiais, no caso, estruturas clivadas.

\section{CONSIDERAÇÕES FINAIS}

Este trabalho teve como foco o estudo comparativo da estrutura entoacional das sentenças neutras com a estrutura entoacional das estruturas clivadas (sentenças clivadas, clivadas invertidas e clivadas invertidas reduzidas) do PB. Tal estudo comparativo buscou confirmar ou infirmar a hipótese de que, assim como em PE (cf. Frota, 1994; Vigário, 1998; Fernandes-Svartman, 2007c), também em PB, estruturas sintáticas especiais, como o caso das sentenças clivadas, clivadas invertidas e clivadas invertidas reduzidas, podem ser codificadas prosodicamente através do contorno entoacional.

Os resultados alcançados por este trabalho confirmam tal hipótese na medida em que foi atestado que o contorno entoacional associado às estruturas clivadas do PB sofre grandes alterações se comparado ao contorno entoacional associado às sentenças neutras da mesma variedade. Para as sentenças neutras foram encontrados acentos tonais associados a, praticamente, cada palavra prosódica da sentença (alta densidade tonal) e ausência de acentos frasais associados a fronteiras de frases fonológicas. Por outro lado, no caso das es- 
truturas clivadas, foram encontradas as seguintes características entoacionais: acento tonal associado obrigatoriamente à palavra prosódica cabeça da frase fonológica na qual o sujeito focalizado é mapeado, acento frasal associado opcionalmente à fronteira direita dessa mesma frase fonológica e ausência de acentos tonais associados a palavras prosódicas intermediárias (entre a palavra prosódica cabeça da frase fonológica na qual o sujeito focalizado é mapeado e a palavra prosódica cabeça da última frase fonológica da frase entoacional). Essa última característica entoacional explica a baixa densidade tonal encontrada para as estruturas clivadas do PB.

Quanto à associação de acentos frasais ao contorno entoacional das estruturas clivadas do PB, cabe ainda tecermos alguns comentários. Nas estruturas clivadas do PB, apenas foram encontrados acentos frasais associados a fronteiras de frases fonológicas nas quais o sujeito focalizado era mapeado e em mais nenhum outro tipo de frase fonológica das mesmas sentenças foram encontrados acentos frasais associados às suas fronteiras. Além disso, não foram encontrados acentos frasais associados a fronteiras de frases fonológicas das sentenças neutras. Nossa hipótese é que esses acentos frasais, encontrados apenas nas estruturas clivadas e associados a fronteiras de frases fonológicas específicas (fronteira da frase fonológica na qual o sujeito focalizado é mapeado), desempenhem um papel importante na codificação prosódica de uma estrutura sintática especial associada às estruturas clivadas do PB. Assumindo a perspectiva sintática da teoria da gramática (cf. Chomsky, 1981; entre outros), é possível conjecturar que o acento frasal associado à fronteira direita da frase fonológica na qual o sujeito focalizado é mapeado codifique, prosodicamente, uma posição sintática diferente, se comparada à posição ocupada pelo sujeito nas sentenças neutras (no caso, posição de especificador de IP), ${ }^{10}$ ocupada por esse sujeito: fora de IP, na posição de especificador de $\mathrm{CP},{ }^{11}$ como ilustram as

10 Não trataremos aqui da posição ocupada pelo sujeito em IP, considerando a hipótese do IP cindido. Sobre este tema, especificamente para o português, cf. Galves (1993, 2001); Figueiredo Silva (1996); Kato (1999, 2000); Costa e Galves (2002); Tavares Silva (2004); entre outros.

11 Quanto às categorias sintáticas IP, Sintagma Flexional (do inglês, Inflexional Phrase), e CP, Sintagma Complementizador (do inglês, Complementizer Phrase), acrescentamos que, na perspectiva de teoria da gramática, em sua versão de Princípios e Parâmetros (cf. Chomsky, 1981, entre outros) - quadro teórico assumido neste trabalho -, IP é o sintagma cujo núcleo (o verbo) checa seus traços funcionais (em português: nome, número, aspecto e 
representações sintáticas abaixo para as sentenças clivada, clivada invertida e clivada invertida reduzida apresentadas respectivamente em (5), (6) e (7) deste trabalho. $^{12}$

(8) $\quad{ }_{\mathrm{IP}}$ pro foram $\left[_{\mathrm{CP}}\right.$ as venezuelanas que $_{\mathrm{IP}_{\mathrm{P}}} \mathrm{t}_{\mathrm{i}}$ lavaram as luvas $\left.]\right]^{111213}$

(9) ${ }_{\mathrm{CP}}$ As velhas ${ }_{\mathrm{i}}$ é ${ }_{\mathrm{CP}}$ que $\left[_{\text {IP }} \mathrm{t}_{\mathrm{i}}\right.$ choraram $\left.\left.]\right]\right]$

(10) $\left[_{\mathrm{CP}}\right.$ As alunas jovens ${ }_{\mathrm{i}}$ que $\left[_{\mathrm{IP}} \mathrm{t}_{\mathrm{i}}\right.$ chegaram hoje $\left.]\right]$

Os resultados aqui apresentados relativos à codificação prosódica da posição sintática ocupada pelo sujeito das diferentes estruturas clivadas do PB trazem importantes contribuições aos estudos sobre a interface sintaxe-fonologia da mesma variedade do português, em especial, aos estudos que buscam, na fonologia (mais especificamente, na prosódia), pistas que possam confirmar ou infirmar certo tipo de representação sintática proposto para dada sentença que, em princípio, poderia ser representada por mais de um tipo de representação sintática, como, por exemplo, no caso das representações sintáticas de sentenças clivadas e relativas do PB. O que tem sido afirmado frequentemente na literatura sintática sobre essas sentenças é que toda clivada contém uma relativa. No entanto, trabalhos recentes já vão em direção oposta a essa afirmação (cf. Mioto e Negrão, 2008; Oliveira, 2011). Esses últimos trabalhos apontam que é necessário que se observe a leitura semântica das estru-

pessoa) e CP, acima de IP, é responsável por alojar, em seu núcleo, elementos ligadores de sentença e, na sua posição de especificador, elementos movidos de dentro da categoria IP. Tanto IP como CP sofreram cisão em Princípios e Parâmetros, logo, por exemplo, na categoria CP, alojam-se sintagmas como tópico e foco em posições específicas do que se chama hoje de CP explodido.

12 Sobre a derivação sintática das estruturas clivadas do PB, cf. Kato e Raposo (1996); Modesto (2001); Kato e Mioto (2005); Fernandes (2007a); entre outros.

13 Nas representações sintáticas apresentadas em (8), (9) e (10), os sujeitos focalizados (clivados) estão sendo inseridos na categoria CP de maneira simplificada. Isso porque não faz parte do escopo deste trabalho explicitar em qual categoria do CP, considerando CP explodido - ver Rizzi (1997), os sujeitos clivados se encontram. 
turas clivadas e que somente as estruturas clivadas com leitura especificacional é que deveriam ser chamadas de clivadas. Tais trabalhos corroboram Modesto (2001), que faz uma distinção entre estruturas clivadas e copulativas do PB. Às estruturas clivadas, em que se atesta foco, não se pode, portanto, atribuir uma estrutura de relativa; diferentemente, nas estruturas copulativas, em que não se atesta foco, as estruturas relativas podem ser encontradas. Esses trabalhos trazem importantes avanços no que se refere à interface sintaxe-semântica. Porém, faz-se ainda necessário que se acrescentem resultados, para essas mesmas estruturas do PB, advindos de estudos desenvolvidos no âmbito da interface sintaxe-fonologia. Em outras palavras, se é verdade que há diferença entre estrutura copulativa e de clivagem, é bem provável que a estrutura prosódica da língua marque essa diferença. Isso posto, configura-se como desdobramento do presente trabalho, e como objetivo da próxima etapa de nossa pesquisa, o estudo sistemático e comparativo da estrutura prosódica associada às sentenças clivadas, em que se atesta foco, e da estrutura prosódica associada às sentenças copulativas, em que não se atesta foco, de maneira a contribuir com evidências prosódicas para a proposição de representações sintáticas diferentes (ou não) para esses dois tipos de sentenças do PB.

\section{BIBLIOGRAFIA}

BECKMAN, M.; PIERREHUMBERT, J. 1986. Intonational structure in Japanese and English. Phonology Yearbook 3.

CHOMSKY, N. 1981. Lectures on Government and Binding. Dordrecht: Foris.

COSTA, J.; GALVES, C. M. C. 2002. External subjects in two varieties of Portuguese evidence for a non-unified analysis. In: BEYSSADE, C. et al. (Orgs.). Romance languages and linguistic theory 2000, v. 232. Amsterdam/Philadelphia: John Benjamins Publishing Company.

CUNHA, G. 2000. Entoação regional no Português do Brasil. Rio de Janeiro. Tese (Doutorado) - Universidade Federal do Rio de Janeiro.

FERNANDES, F. R. 2007a. Ordem, focalização e preenchimento em português: sintaxe e prosódia. Campinas. Tese (Doutorado) - Universidade Estadual de Campinas.

2007b. Tonal association of neutral and subject-narrow-focus sentences in

Brazilian Portuguese: a comparison with European Portuguese. Journal of Portuguese Linguistics 5/6. 91-115.

FERNANDES-SVARTMAN, F. R. 2007c. Entoação e domínios prosódicos em sentenças pseudo-clivadas do português europeu. Letras de Hoje 42. 69-88. 
FIGUEIREDO SILVA, M. C. 1996. A posição sujeito no português brasileiro: frases finitas e infinitivas. Campinas: Editora da Unicamp.

FROTA, S. 1994. Aspectos da prosódia do foco no português europeu. Letras de Hoje 98. 2000. Prosody and focus in European Portuguese. Phonological phrasing and intonation. New York: Garland Publishing.

; VIGÁRIO, M. 2000. Aspectos de prosódia comparada: ritmo e entoação no PE e no PB. In: CASTRO, R. V.; BARBOSA, P. (eds.). Actas do XV Encontro Nacional da Associação Portuguesa de Linguística. Coimbra: APL.

GALVES, C. M. C. 1993. O enfraquecimento da concordância no português brasileiro. In: ROBERTS, I.; KATO, M. (Orgs.). Português brasileiro: uma viagem diacrônica. Campinas: Editora da Unicamp.

. 2001. Ensaios sobre as gramáticas do português. Campinas: Editora da Unicamp.

JUN, S-A. 2005. Prosodic Typology - The Phonology of Intonation and Phrasing. New York: Oxford University Press.

$1-37$.

1999. Strong and weak pronominals in the null subject parameter. Probus 11.

The partial pro-drop nature and the restricted VS order in Brazilian Portuguese. In: KATO, M.; NEGRÃO, E. (Eds.). 2000. Braqilian Portuguese and the Null Subject Parameter. Madrid: Iberoamericana.

; MIOTO, C. 2005. A multi-evidence study of European and Brazilian Portuguese wh-questions. In: KEPSER, S.; REIS, M. (orgs.). Linguistic evidence: empirical, theoretical and computational perspectives. Berlin/New York: Mouton de Gruyter.

; RAPOSO, E. 1996. European and Brazilian word order: questions, focus and topic constructions. In: PARODI, C.; QUICOLI, A. C.; SALTARELLI, M.; ZUBIZARRETA, M. L. (Eds.). Aspects of Romance Linguistics. Washington: Georgetown, University Press.

LADD, D. R. 1996. Intonational Phonology. Cambridge: CUP.

MIOTO, C.; NEGRÃO, E. V. 2007. As sentenças clivadas não contêm uma relativa. In: CASTILHO, A. T.; TORRES MORAIS, M. A.; LOPES, R. E. V.; CYRINO, S. M. L. (Org.). Descrição, história e aquisição do português brasileiro. Campinas: Pontes Editores.

MODESTO, M. 2001. As construções clivadas no português do Brasil: relações entre interpretação focal, movimento sintático e prosódia. São Paulo: Humanitas.

NESPOR, M.; VOGEL, I. 1986. Prosodic Phonology. Dordrecht: Foris Publications.

OLIVEIRA, M. S. D. 2011. Focus in Brazilian Portuguese. In: PETTER, M. M. T.; VANHOVE, M. (Org.). Portugais et langues africaines. Etudes afro-brésieliennes. Paris: Karthala.

PIERREHUMBERT, J. 1980. The phonology and phonetics of English intonation. Massachusetts. Tese (Doutorado) - M. I. T. 
RIZZI, L. 1997. The fine structure of left periphery. In: HAEGEMAN, L. (Ed.). Elements of grammar. Dordrecht: Kluwer.

SCHWINDT, L. C. 2001. O prefixo no Português Brasileiro: análise prosódica e lexical. D.E.L.T.A. 17.

SELKIRK, E. O. 1986. On derived domains in sentence phonology. Phonology Yearbook 3. 371-405.

; 1995. The prosodic structure of function words. In: BECKMAN, J. N. ; DICKEY, L. W.; URBANCZYK, S. (Eds.). Papers in Optimality Theory. University of Massachusetts, Amherst, GLSA.

; 2000. The interaction of constraints on prosodic phrasing. In: HORNE, M. (Ed.). Prosody: Theory and Experiment. Netherlands: Kluwer Academic Publishers.

SERRA, C. R. 2009. Realização e percepção de fronteiras prosódicas no português do Brasil: fala espontânea e leitura. Rio de Janeiro. Tese (Doutorado) - Universidade Federal do Rio de Janeiro.

TAVARES SILVA, C. R. 2004. A Natureza de AGR e suas implicações na ordem VS: um estudo comparativo entre o português brasileiro e o português europeu. Alagoas. Tese (Doutorado) - Universidade Federal de Alagoas.

TENANI, L. E. 2002. Domínios prosódicos no Português do Brasil: implicações para a prosódia e para a aplicação de processos fonológicos. Campinas. Tese (Doutorado) - Universidade Estadual de Campinas.

; FERNANDES-SVARTMAN, F. R. 2008. Prosodic phrasing and intonation in neutral and subject-narrow-focus sentences of Brazilian Portuguese. Proceedings of Fourth Conference on Speech Prosody 2008. Campinas: RG/CNPq.

TONELI, P. M. 2009. A palavra prosódica no PB: o estatuto prosódico das palavras funcionais. 2009. Campinas. Dissertação (Mestrado em Linguística) - Universidade Estadual de Campinas.

VIGÁRIO, M. 1998. Aspectos da Prosódia do Português Europeu: estruturas com advérbio de exclusão e negação frásica. Braga: CEHUM.

VIGÁRIO, M. 2003. The Prosodic Word in European Portuguese. Berlin-New York: Mouton de Gruyter. 


\title{
Intomation of cleft sentences in Brazilian Portuguese and the syntax-phonology interface
}

\begin{abstract}
This study, developed within the theoretical framework of Intonational Phonology (cf. Pierrehumbert, 1980; Beckman and Pierrehumbert, 1986; Ladd 1996; Jun, 2005), is a comparative study of the intonational structure of neutral and cleft sentences (cleft, inverted cleft, and reduced inverted cleft sentences) in Brazilian Portuguese (hereafter PB). According to results obtained by Frota (1994), Vigário (1998) and Fernandes-Svartman (2007c), in special syntactic structures in European Portuguese, the intonational contour undergoes local, and sometimes global alteration, compared to the contour of neutral sentences. Our hypothesis is that alteration in the intonational contour in special syntactic structures also occurs in PB, as is the case with cleft sentences. The results attained by this study confirm this hypothesis, to the extent that significant differences between the intonational contour of neutral sentences and the intonational contour of cleft sentences in PB were found. While neutral sentences showed tonal accents associated with practically each prosodic word of the sentence, and an absence of phrasal accents associated with boundaries of phonological phrases, cleft sentences showed: (i) tonal accent obligatorily associated with the head prosodic word of the phonological phrase in which the focused subject is mapped; (ii) phrasal accent optionally associated with the right boundary of this same phonological phrase; and (iii) absence of tonal accents associated with intermediary prosodic words (between the head prosodic word of the phonological phrase in which the focused subject is mapped and the head prosodic word of the last phonological of the intonational phrase). In the case of the cleft sentences, the presence of a phrasal accent associated with the right boundary of the phonological phrase in which the focused subject is mapped may, theoretically, be related to the codification of a special syntactic position occupied by this subject in such structures: outside the IP, in the CP specifier position.
\end{abstract}

Keywords: Brazilian Portuguese; Cleft Sentences; Intonation; Phonology .

Recebido em: 09/11/2011

Aprovado em: 06/04/2012 